\title{
Analysis of elements and bacosides in in vitro shoot culture of Bacopa monnieri
}

\author{
M. Lojewski ${ }^{1}$ A. Krakowska² ${ }^{2}$ W. Reczyński ${ }^{2}$ A. Szewczyk $^{1} \cdot$ B. Muszyńska ${ }^{1}$
}

Received: 7 October 2015/Revised: 20 April 2016/Accepted: 25 May 2016/Published online: 3 June 2016

(c) The Author(s) 2016. This article is published with open access at Springerlink.com

\begin{abstract}
The experiments on Bacopa monnieri from Scrophulariaceae family were performed in in vitro shoot cultures conditions in media enriched with $\mathrm{Mg}$ ions and serine or anthranilic acid (L1 vitamin). As there is limited literature data available on the content of elements in shoots from B. monnieri in vitro cultures, analyses of magnesium, zinc, potassium, calcium, copper, sodium and iron in plant shoots constituted the aim of the present study. The next aim of the work, for the first time, consists of evaluation of the content and concentration of magnesium and other metals in in vitro shoot cultures of $B$. monnieri and their influence on bacoside levels, as well as establishment of interactions between the listed analytes. The highest accumulation of magnesium was determined in the plant tissues cultured in media doped with $0.1 \mathrm{~g} / \mathrm{L}$ serine and $0.5 \mathrm{~g} / \mathrm{L} \mathrm{Mg}(2104 \mu \mathrm{g} / \mathrm{g}$ dry weight), and $0.5 \mathrm{mg} / \mathrm{g}$ of anthranilic acid and $1.0 \mathrm{~g} / \mathrm{L} \mathrm{Mg}(2163 \mu \mathrm{g} / \mathrm{g})$. The highest concentration of bacosides in the obtained in vitro shoot cultures of B. monnieri (37.3 mg/g dry weight) was found in cultures of the following media composition: MS1 with addition of $0.25 \mathrm{~g} / \mathrm{L}$ serine and $0.1 \mathrm{~g} / \mathrm{L} \mathrm{Mg}$, and MS1 with addition of $0.5 \mathrm{~g} / \mathrm{L}$ serine and $0.5 \mathrm{~g} / \mathrm{L}$ magnesium. Considering the observed shortage of plant reserves in the natural environment and its curative properties, it seems to be of utmost importance to obtain, as a result of the
\end{abstract}

Communicated by J. van Staden.

B. Muszyńska

muchon@poczta.fm

1 Department of Pharmaceutical Botany, Jagiellonian University Collegium Medicum, Medyczna St 9, Kraków 30-688, Poland

2 Faculty of Materials Science and Ceramics, AGH University of Science and Technology, Cracow, Poland presented experiment, in vitro shoot cultures of B. monnieri characterized by optimal and reproducible composition of the physiologically active elements and metabolites.

Keywords Bacopa monnieri - Bacosides · In vitro culture · Magnesium ions

\section{Introduction}

Bacopa monnieri (L.) Pennell-Brahmi from Scrophulariaceae family is one of the most important plants in the traditional Hindu system of medicine, Ayurveda. B. monnieri is used in India for 5000 years to treat epilepsy and insomnia, as a sedative and abolishing raw anxiety (Gohil and Patel 2010). Indian materia medica (Bhavaprakasha Nighantu 1500 years $\mathrm{AD}$ ). It recommends this material as a means of improving memory and concentration (Biswas et al. 2012; Singh 2013). Commercially available preparations of $B$. monnieri improve brain function, concentration and memory in both young and older people (Vangalapati et al. 2011). Clinical studies confirm beneficial effects of this species in recovering of mental functions in children suffering from ADHD (attention deficit hyperactivity disorder), improving the cognitive functions in patients after stroke and epilepsy (Gohil and Patel 2010). Based on the previous studies, it is believed that these effects are due to the ability of the plant extracts to modulate humans' cholinergic system (Jyoti and Sharma 2006). Plant extracts increase blood flow in brain, improve concentration, they have antioxidant, anti-inflammatory, antibacterial, and antitumor effects, and they are also used as a support in neurodegenerative diseases (such as Alzheimer's and Parkinson's diseases) therapies (Kamkaew et al. 2013; Shah et al. 2012; Wasnik 2012; Ravikumar et al. 2005; Sumathi et al. 2012). Compounds, which are attributed 
to the abovementioned actions, are bacosides and triterpenoids, belonging to the saponins (Gohil and Patel 2010).

Extracts from $B$. monnieri are used for blood purification from heavy metals due to their ability to chelate them (Ahire et al. 2013). This raises the possibility of obtaining raw material enriched in beneficial to human body compounds (anthranilic acid and serine, which are precursors of many plant metabolites) and micronutrients $(\mathrm{Mg})$ for the targeted physiological effects.

The fresh material might be more effective in treatment of diseases. Due to limited information on the content of macro and microelements in the fresh material of B. monnieri, it is necessary to determine them quantitatively and to assess their ability to accumulate in this material under fully controlled conditions of in vitro culture. To study accumulation of the bioelements in shoots of B. monnieri, it was necessary to develop an appropriate in vitro culture medium composition and culture conditions. Thus, for the first time, magnesium, zinc, potassium, calcium, copper, sodium and iron were determined quantitatively in B. monnieri. These bioelements were chosen because of their physiological function (playing important role in human metabolism by building blocks and being enzymes activators) which can explain this plant activity. Magnesium, being the second most abundant intracellular cation after potassium, is an essential ion for life. $\mathrm{Mg}^{2+}$ has important cellular functions in enzymatic reactions (De Baaij et al. 2015). Zinc has a large number of physiological roles, especially in growth and functioning of the immune system (Livingstone 2015). Potassium and sodium have influence on multiple physiological processes; one of them is resting cellular membrane potential and osmoregulation. Calcium is a bone builder and also an enzymatic activator (Allen 1982). Copper proteins have diverse roles in biological electron transport and oxygen transportation and this element is a part of superoxide dismutase. Iron is an element which is located in the center of such enzymes like catalase, peroxidase and cytochrome.

The work was performed with the aim to determine in in vitro culture conditions of B. monnieri: (a) bio elements concentrations in in vitro shoot cultures of $B$. monnieri; (b) the influence of culture medium composition on macroand microelements accumulation in in vitro shoot cultures of B. monnieri, (c) the influence of $\mathrm{Mg}$, serine and anthranilic acid on bacosides content in in vitro shoot cultures of B. monnieri.

\section{Materials and methods}

\section{Plant material}

The studies were conducted on the in vitro shoot cultures of B. monnieri (B. monnieri biomass). The in vitro cultures were established from commercially available in vitro cultures of $B$. monnieri from IVPLANT (representative samples of in vitro shoot cultures of $B$. monnieri were deposited at the Department of Pharmaceutical Botany, Jagiellonian University Collegium Medicum, Kraków, Poland). This material was identified by a botanist Bożena Muszyńska. Shoots were cut into $2 \mathrm{~cm}$ shoot pieces and placed in the Erlenmeyer flasks with $100 \mathrm{~mL}$ of liquid medium (MS) according to Murashige and Skoog (1962) with our modifications. The modifications consisted in the addition of nicotinic acid $(0.5 \mathrm{mg} / \mathrm{L})$, myo-inositol (100 mg/L), vitamin $\mathrm{B}_{1}(4.0 \mathrm{mg} / \mathrm{L})$, and growth regulators: 6-benzylaminopurine (BAP) $1.0 \mathrm{mg} / \mathrm{L}$ and 1-naphthaleneacetic acid (NAA) $0.2 \mathrm{mg} / \mathrm{L}, \mathrm{pH}$ was adjusted to $5.7-5.8$ before autoclaving. This was the basal medium (MS1) and shoots were sub cultured every 4 weeks.

\section{Experimental in vitro cultures}

The in vitro shoot cultures of $B$. monnieri were used to obtain the experimental in vitro cultures. The experiment was conducted using the basic medium (MS1) as a reference and the medium with additions of anthranilic acid or serine (both in concentrations: $0.1 ; 0.25 ; 0.5 ; 0.75 ; 1.0 \mathrm{mg} / \mathrm{L})$. In this experiment, to the MS1 medium of in vitro shoot cultures of B. monnieri, magnesium sulfate $(\mathrm{Mg})$ in concentrations: $0.01 ; 0.1 ; 0.25 ; 0.5 ; 1.0 \mathrm{mg} / \mathrm{L}$ was also added (the compositions of cultures media are given in Table 1). Cultures were grown under constant artificial light $\left(4 \mathrm{~W} / \mathrm{m}^{2}, \mathrm{LF}-40 \mathrm{~W}\right.$ lamp, daylight, Piła) at $25 \pm 2{ }^{\circ} \mathrm{C}$. After 4 weeks, the fresh biomass was collected, frozen, and lyophilized (lyophilizer FreeZone 4.5, Labconco; temperature $-40^{\circ} \mathrm{C}$ ). After lyophilization, the plant material was weighed ( $1 \mathrm{~g}$ of each) and grounded in an agate mortar. Then, the powdered dry material was used for qualitative and quantitative RP-HPLC analysis of bacosides and quantitative determination of the chosen elements: $\mathrm{Mg}, \mathrm{Zn}, \mathrm{K}, \mathrm{Ca}, \mathrm{Cu}, \mathrm{Na}$, and $\mathrm{Fe}$ by means of atomic absorption spectrometry.

\section{RP-HPLC analysis of bacosides}

The powdered shoots $(5 \mathrm{~g})$ from in vitro shoot cultures of B. monnieri were subjected to extraction with methanol (10 portions of $100 \mathrm{~mL}$ ) in a percolator. Methanolic extract was left in room temperature to dry. The residue was quantitatively dissolved in methanol $(14 \mathrm{~mL})$, filtered through Millipore Millex-GP, $0.22 \mu \mathrm{m}$ and was subjected to RP-HPLC analysis.

RP-HPLC analyses were conducted according to described elsewhere (Srivastava et al. 2012) with our modifications, using a Merck Hitachi liquid chromatography (LaChrom Elite) equipped with a DAD detector L-2455 and Purospher ${ }^{\circledR}$ RP-18e $(250 \times 4 \mathrm{~mm} / 5 \mu \mathrm{m})$ 
Table 1 Concentrations of bioelements and bacosides in in vitro culture of B. monnieri ( $\mu \mathrm{g} / \mathrm{g}$ DW)

\begin{tabular}{|c|c|c|c|c|c|c|c|c|}
\hline \multirow[t]{2}{*}{ Supplement Mg (g/L) } & \multicolumn{7}{|c|}{ Concentration $(\mu \mathrm{g} / \mathrm{g} \mathrm{DW})$} & \multirow{2}{*}{$\begin{array}{l}\text { Bacosides } \\
(\mathrm{mg} / \mathrm{g} \mathrm{DW})\end{array}$} \\
\hline & $\mathrm{Mg}$ & $\mathrm{Zn}$ & $\mathrm{K}$ & $\mathrm{Ca}$ & $\mathrm{Cu}$ & $\mathrm{Na}$ & $\mathrm{Fe}$ & \\
\hline \multicolumn{9}{|l|}{ B } \\
\hline & $617.8 \pm 1.0$ & $110.1 \pm 2.0$ & $12,300 \pm 1.8$ & $1294 \pm 1.1$ & $1.102 \pm 0.2$ & $355.2 \pm 4.2$ & $103.2 \pm 2.8$ & $27.1 \pm 0.7$ \\
\hline \multicolumn{9}{|l|}{$0.1 \mathrm{~S}(\mathrm{~g} / \mathrm{L})$} \\
\hline- & $620.6 \pm 0.2$ & $102.5 \pm 0.2$ & $24,120 \pm 0.3$ & $1329 \pm 0.4$ & $1.218 \pm 0.2$ & $689.2 \pm 1.2$ & $156.4 \pm 0.2$ & $32.6 \pm 0.8$ \\
\hline $0.01 \mathrm{Mg}$ & $1628 \pm 0.1$ & $177.5 \pm 0.5$ & $25,100 \pm 3.3$ & $1836 \pm 1.7$ & $1.996 \pm 1.5$ & $1125 \pm 0.4$ & $206.5 \pm 1.3$ & $19.6 \pm 1.2$ \\
\hline $0.1 \mathrm{Mg}$ & $1763 \pm 0.1$ & $140.7 \pm 0.9$ & $48,530 \pm 1.3$ & $1860 \pm 0.1$ & $2.480 \pm 2.5$ & $580.8 \pm 0.3$ & $211.8 \pm 0.4$ & $27.7 \pm 1.6$ \\
\hline $0.5 \mathrm{Mg}$ & $2104 \pm 0.6$ & $145.6 \pm 2.1$ & $37,050 \pm 0.3$ & $1514 \pm 0.5$ & $1.512 \pm 7.4$ & $574.1 \pm 0.4$ & $204.9 \pm 0.2$ & $29.6 \pm 1.9$ \\
\hline \multicolumn{9}{|l|}{$0.25 \mathrm{~S}(\mathrm{~g} / \mathrm{L})$} \\
\hline- & $690.1 \pm 0.1$ & $112.3 \pm 0.5$ & $27,950 \pm 1.3$ & $1414 \pm 1.1$ & $1.184 \pm 0.4$ & $721.3 \pm 0.2$ & $132.1 \pm 1.3$ & $21.0 \pm 0.3$ \\
\hline $0.01 \mathrm{Mg}$ & $1472 \pm 0.3$ & $136.7 \pm 0.2$ & $31,610 \pm 1.7$ & $1640 \pm 0.1$ & $2.394 \pm 1.6$ & $1502 \pm 1.6$ & $233.9 \pm 0.2$ & $26.8 \pm 0.1$ \\
\hline $0.1 \mathrm{Mg}$ & $1648 \pm 0.2$ & $134.9 \pm 0.4$ & $37,420 \pm 2.2$ & $1452 \pm 0.7$ & $2.560 \pm 2.0$ & $1204 \pm 2.2$ & $208.6 \pm 0.5$ & $37.3 \pm 1.7$ \\
\hline $0.5 \mathrm{Mg}$ & $2070 \pm 0.7$ & $176.6 \pm 0.1$ & $28,570 \pm 0.6$ & $1518 \pm 0.4$ & $2.543 \pm 6.6$ & $552.1 \pm 0.8$ & $122.1 \pm 0.1$ & $35.2 \pm 1.6$ \\
\hline \multicolumn{9}{|l|}{$0.5 \mathrm{~S}(\mathrm{~g} / \mathrm{L})$} \\
\hline- & $1249 \pm 1.1$ & $119.4 \pm 1.2$ & $25,790 \pm 1.6$ & $1216 \pm 0.2$ & $1.113 \pm 0.1$ & $856.7 \pm 1.1$ & $158.1 \pm 0.6$ & $20.8 \pm 0.6$ \\
\hline $0.01 \mathrm{Mg}$ & $1286 \pm 0.5$ & $175 \pm 0.6$ & $25,840 \pm 0.1$ & $1624 \pm 0.6$ & $1.526 \pm 1.3$ & $1289 \pm 0.4$ & $157.2 \pm 0.9$ & $28.0 \pm 1.3$ \\
\hline $0.1 \mathrm{Mg}$ & $1754 \pm 0.5$ & $173.1 \pm 0.9$ & $32,780 \pm 0.4$ & $1795 \pm 0.2$ & $1.877 \pm 4.0$ & $1315 \pm 1.3$ & $204.2 \pm 1.2$ & $32.9 \pm 1.3$ \\
\hline $0.5 \mathrm{Mg}$ & $1709 \pm 0.1$ & $131.1 \pm 0.2$ & $24,550 \pm 0.6$ & $1124 \pm 0.6$ & $1.183 \pm 1.1$ & $823.7 \pm 0.1$ & $74.07 \pm 2.3$ & $37.3 \pm 2.0$ \\
\hline \multicolumn{9}{|l|}{$0.75 \mathrm{~S}(\mathrm{~g} / \mathrm{L})$} \\
\hline- & $1296 \pm 0.1$ & $144.2 \pm 0.4$ & $17,450 \pm 0.8$ & $1120 \pm 0.1$ & $1.151 \pm 0.3$ & $989.4 \pm 2.1$ & $189.5 \pm 1.6$ & $18.4 \pm 0.6$ \\
\hline $0.01 \mathrm{Mg}$ & $1465.9 \pm 0.4$ & $146.3 \pm 1.2$ & $13,500 \pm 2.0$ & $1154.3 \pm 0.8$ & $1.248 \pm 3.8$ & $680.1 \pm 0.8$ & $92.44 \pm 0.2$ & $25.5 \pm 0.9$ \\
\hline $0.1 \mathrm{Mg}$ & $1427 \pm 0.5$ & $176.3 \pm 0.2$ & $27,130 \pm 0.5$ & $1578 \pm 0.7$ & $1.247 \pm 1.6$ & $1258 \pm 0.1$ & $137.1 \pm 1.1$ & $34.7 \pm 1.7$ \\
\hline $0.5 \mathrm{Mg}$ & $1474 \pm 0.1$ & $164.3 \pm 1.8$ & $26,870 \pm 0.6$ & $1357 \pm 0.5$ & $1.517 \pm 1.8$ & $1004 \pm 0.6$ & $239.7 \pm 1.5$ & $30.8 \pm 1.4$ \\
\hline \multicolumn{9}{|l|}{$1.0 \mathrm{~S}(\mathrm{~g} / \mathrm{L})$} \\
\hline- & $1002 \pm 0.4$ & $146.1 \pm 0.4$ & $16,807 \pm 0.4$ & $987.7 \pm 0.5$ & $1.298 \pm 0.4$ & $1011 \pm 0.6$ & $145.8 \pm 0.2$ & $26.8 \pm 1.5$ \\
\hline $0.01 \mathrm{Mg}$ & $1051 \pm 0.4$ & $168.3 \pm 0.2$ & $21,580 \pm 0.3$ & $1080 \pm 0.2$ & $1.423 \pm 2.8$ & $1224 \pm 0.2$ & $140.2 \pm 0.2$ & $19.8 \pm 0.9$ \\
\hline $0.1 \mathrm{Mg}$ & $1070 \pm 0.7$ & $159.3 \pm 0.5$ & $27,270 \pm 1.2$ & $1185 \pm 0.7$ & $0.837 \pm 1.8$ & $1329.9 \pm 0.1$ & $132.9 \pm 0.9$ & $33.2 \pm 1.4$ \\
\hline $0.5 \mathrm{Mg}$ & $1081 \pm 0.2$ & $189.3 \pm 0.5$ & $17,540 \pm 0.2$ & $1040 \pm 1.6$ & $1.411 \pm 0.1$ & $759 \pm 0.6$ & $158.8 \pm 1.4$ & $32.9 \pm 1.0$ \\
\hline \multicolumn{9}{|l|}{$0.1 \mathrm{~A}(\mathrm{~g} / \mathrm{L})$} \\
\hline- & $840.7 \pm 0.1$ & $64.47 \pm 1.9$ & $26,040 \pm 0.5$ & $2451 \pm 0.1$ & $2.006 \pm 2.5$ & $808.4 \pm 1.2$ & $143.2 \pm 0.4$ & $35.2 \pm 1.5$ \\
\hline $0.25 \mathrm{Mg}$ & $1367 \pm 0.2$ & $128.1 \pm 1.6$ & $37,410 \pm 0.7$ & $2472 \pm 0.1$ & $2.460 \pm 4.6$ & $709.1 \pm 2.9$ & $178.5 \pm 2.0$ & $19.9 \pm 1.9$ \\
\hline $0.5 \mathrm{Mg}$ & $1859 \pm 1.3$ & $118.9 \pm 0.2$ & $43,790 \pm 1.5$ & $2596 \pm 0.8$ & $2.460 \pm 5.2$ & $702.4 \pm 0.8$ & $145.9 \pm 0.3$ & $23.7 \pm 2.3$ \\
\hline $1.0 \mathrm{Mg}$ & $1955 \pm 0.1$ & $84.10 \pm 0.2$ & $49,370 \pm 2.1$ & $1773 \pm 0.1$ & $1.992 \pm 2.1$ & $487.8 \pm 0.1$ & $140.5 \pm 0.1$ & $20.3 \pm 0.7$ \\
\hline \multicolumn{9}{|l|}{$0.25 \mathrm{~A}(\mathrm{~g} / \mathrm{L})$} \\
\hline- & $700.4 \pm 0.1$ & $57.72 \pm 2.1$ & $23,480 \pm 0.7$ & $1858 \pm 1.3$ & $1.340 \pm 7.6$ & $646.2 \pm 0.8$ & $169.4 \pm 0.7$ & $27.8 \pm 1.2$ \\
\hline $0.25 \mathrm{Mg}$ & $1174 \pm 4.9$ & $121.4 \pm 0.3$ & $43,370 \pm 1.7$ & $2915 \pm 0.4$ & $2.068 \pm 0.4$ & $538.5 \pm 2.7$ & $136.2 \pm 1.2$ & $19.5 \pm 0.9$ \\
\hline $0.5 \mathrm{Mg}$ & $1600 \pm 4.2$ & $127.0 \pm 1.1$ & $50,590 \pm 1.1$ & $2329 \pm 0.5$ & $2.003 \pm 4.7$ & $606.4 \pm 1.5$ & $188.2 \pm 1.5$ & $22.1 \pm 1.2$ \\
\hline $1.0 \mathrm{Mg}$ & $1964 \pm 2.8$ & $114.7 \pm 0.5$ & $58,970 \pm 1.4$ & $2069 \pm 0.1$ & $2.045 \pm 0.3$ & $400 \pm 0.7$ & $130.2 \pm 0.4$ & $20.6 \pm 0.7$ \\
\hline \multicolumn{9}{|l|}{$0.5 \mathrm{~A}(\mathrm{~g} / \mathrm{L})$} \\
\hline- & $810.4 \pm 0.6$ & $54.75 \pm 0.2$ & $20,560 \pm 0.8$ & $2172 \pm 0.2$ & $1.685 \pm 2.2$ & $769.4 \pm 0.3$ & $178.2 \pm 0.9$ & $29.4 \pm 0.9$ \\
\hline $0.25 \mathrm{Mg}$ & $1621 \pm 1.0$ & $151.7 \pm 0.2$ & $45,290 \pm 3.1$ & $2412 \pm 0.7$ & $1.872 \pm 2.6$ & $339.2 \pm 1.6$ & $259.6 \pm 0.8$ & $19.9 \pm 0.9$ \\
\hline $0.5 \mathrm{Mg}$ & $1677 \pm 0.3$ & $154.5 \pm 0.4$ & $36,670 \pm 0.7$ & $2609 \pm 0.4$ & $2.190 \pm 1.6$ & $501.4 \pm 3.6$ & $177.4 \pm 0.9$ & $20.0 \pm 1.1$ \\
\hline $1.0 \mathrm{Mg}$ & $2163 \pm 1.0$ & $150.5 \pm 0.9$ & $46,870 \pm 1.7$ & $2264 \pm 0.2$ & $2.064 \pm 0.2$ & $698.2 \pm 1.4$ & $250.0 \pm 1.6$ & $22.6 \pm 1.1$ \\
\hline \multicolumn{9}{|l|}{$0.75 \mathrm{~A}(\mathrm{~g} / \mathrm{L})$} \\
\hline- & $836.2 \pm 0.1$ & $60.3 \pm 0.6$ & $21,420 \pm 0.7$ & $2056 \pm 1.8$ & $1.437 \pm 2.0$ & $723.6 \pm 1.9$ & $184.2 \pm 0.5$ & $30.0 \pm 1.2$ \\
\hline $0.25 \mathrm{Mg}$ & $1027 \pm 1.4$ & $102.1 \pm 2.1$ & $36,270 \pm 1.2$ & $2141 \pm 0.6$ & $2.976 \pm 7.0$ & $691.5 \pm 1.7$ & $182.9 \pm 1.2$ & $18.4 \pm 1.0$ \\
\hline $0.5 \mathrm{Mg}$ & $1733 \pm 1.9$ & $131.4 \pm 5.7$ & $41,370 \pm 5.7$ & $2168 \pm 0.2$ & $2.204 \pm 1.2$ & $461.9 \pm 1.9$ & $504.0 \pm 0.1$ & $21.9 \pm 1.3$ \\
\hline $1.0 \mathrm{Mg}$ & $2083 \pm 0.5$ & $44.32 \pm 3.7$ & $43,910 \pm 4.4$ & $1411 \pm 0.4$ & $1.355 \pm 4.3$ & $285.4 \pm 0.3$ & $63.17 \pm 3.0$ & $23.9 \pm 1.4$ \\
\hline
\end{tabular}


Table 1 continued

\begin{tabular}{|c|c|c|c|c|c|c|c|c|}
\hline \multirow[t]{2}{*}{ Supplement $\mathrm{Mg}(\mathrm{g} / \mathrm{L})$} & \multicolumn{7}{|c|}{ Concentration $(\mu \mathrm{g} / \mathrm{g} D W)$} & \multirow{2}{*}{$\begin{array}{l}\text { Bacosides } \\
(\mathrm{mg} / \mathrm{g} \mathrm{DW})\end{array}$} \\
\hline & $\mathrm{Mg}$ & $\mathrm{Zn}$ & $\mathrm{K}$ & $\mathrm{Ca}$ & $\mathrm{Cu}$ & $\mathrm{Na}$ & $\mathrm{Fe}$ & \\
\hline \multicolumn{9}{|l|}{$1.0 \mathrm{~A}(\mathrm{~g} / \mathrm{L})$} \\
\hline & $710.8 \pm 1.0$ & $62.01 \pm 1.8$ & $22,570 \pm 0.8$ & $968.7 \pm 0.5$ & $0.745 \pm 3.3$ & $670.2 \pm 0.9$ & $137.0 \pm 0.2$ & $30.1 \pm 1.1$ \\
\hline $0.25 \mathrm{Mg}$ & $738.1 \pm 1.9$ & $60.42 \pm 0.4$ & $27,110 \pm 0.8$ & $1269 \pm 0.5$ & $0.878 \pm 4.6$ & $279.2 \pm 0.2$ & $88.78 \pm 1.3$ & $20.9 \pm 1.2$ \\
\hline $0.5 \mathrm{Mg}$ & $1147 \pm 0.2$ & $86.59 \pm 0.7$ & $40,300 \pm 5.1$ & $1787 \pm 0.3$ & $1.217 \pm 6.1$ & $334.4 \pm 0.2$ & $99.26 \pm 0.2$ & $21.4 \pm 1.0$ \\
\hline $1.0 \mathrm{Mg}$ & $1185 \pm 0.9$ & $66.68 \pm 1.7$ & $45,990 \pm 0.5$ & $1323 \pm 1.0$ & $1.127 \pm 1.4$ & $321.8 \pm 0.4$ & $91.60 \pm 2.7$ & $18.4 \pm 0.9$ \\
\hline
\end{tabular}

B-shoot culture in vitro from MS medium (control), '-' medium without Mg ions addition, S-B. monnieri in vitro cultures enriched in serine (in the amounts of $0.1,0.25,0.5,0.75,1.0 \mathrm{~g} / \mathrm{L}$ of serine), $\mathrm{A}-B$. monnieri in vitro cultures enriched in anthranilic acid (in the amounts of 0.1 , $0.25,0.5,0.75,1.0 \mathrm{~g} / \mathrm{L}$ anthranilic acid), Data were presented as the mean $\pm \mathrm{SD} ; n=4$ repetitions

column. Analyses were carried out at $25^{\circ} \mathrm{C}$, with a mobile phase consisting of A-acetonitrile, B-acetonitrile: $0.5 \%$ phosphoric acid $0.01 \mathrm{~mol} / \mathrm{L} 35: 65(\mathrm{v} / \mathrm{v})$, gradient elution: A $(0: 100 \%), \mathrm{B}(100: 0 \%)$ at a flow rate $1 \mathrm{~mL} / \mathrm{min}$, $\lambda=205 \mathrm{~nm}$. Identification was done by comparison of the retention times of the peaks with authentic reference compound and cochromatography with standard. Quantification was done by the measurement of peak area with reference to the standard of bacoside A (bacoside A3, bacopaside II, bacopaside $\mathrm{X}$, bacopasaponin $\mathrm{C}$ ) curve derived from five concentrations $\left(0.1875-3 \mathrm{mg} \mathrm{mL}^{-1}\right)$. An example chromatogram of B. monnieri extract on MS1 medium with $0.5 \mathrm{~g} / \mathrm{L}$ serine addition is shown in Fig. 1.

\section{Sample preparation and quantitative analysis of metals in Bacopa monnieri biomass}

The $0.2 \mathrm{~g}$ samples of lyophilized biomass obtained in in vitro shoot cultures of $B$. monnieri were weighed and wet digested (with addition of $\mathrm{HNO}_{3}$ and $\mathrm{H}_{2} \mathrm{O}_{2}$ ) in a microwave system (Multiwave 3000, Anton Paar, Switzerland). Concentrations of $\mathrm{Mg}, \mathrm{Cu}, \mathrm{Fe}, \mathrm{Ca}$ and $\mathrm{Zn}$ were determined using the flame technique of atomic absorption spectrometry (F AAS) while $\mathrm{K}$ and $\mathrm{Na}$ by means of flame photometry method (AES). The Perkin Elmer atomic absorption spectrometer Model 3110 (USA) was used in all measurements. Each sample was analyzed in quadruplicate, and the results presented below are the mean values. The accuracy and precision of the measurements were tested with the use of the Certified Reference Material, Mixed Polish Herbs No INCT-MPH-2. Satisfactory agreement between the determined and certified elements concentration values was achieved.

\section{Statistical analysis}

Each determination of the analyzed elements concentrations in forty in vitro shoot cultures of $B$. monnieri have been repeated four times. The results are presented as mean values integrated with standard deviations (SD)_-Table 1. All analyses were conducted using Statistica 10 (StatSoft, Poland). To extract significant information about correlations between the measured variables and the objects, chemometric tools [cluster analysis (CA) and principal component analysis (PCA)] have been applied. Statgraphics Centurion XVI (Poland) software was used to perform chemometric analysis. Statistical significance was defined at $p<0.05$.

\section{Results and discussion}

The growth of biomass in in vitro shoot cultures of $B$. monnieri with addition of serine or anthranilic acid (vita$\min \mathrm{L}_{1}$ ) was four times higher than in the same medium cultures enriched with magnesium ions. In each of the above cases, increase of the amount of added $\mathrm{Mg}$ ions caused gradual decrease of biomass growth. Additionally, it was noticed that the most effective growth was obtained for in vitro cultures in which serine and anthranilic acid were added in concentration of $0.1 \mathrm{~g} / \mathrm{L}$. The results are $80.5 \mathrm{~g}$ of biomass for serine and $122.1 \mathrm{~g}$ of biomass for anthranilic acid, respectively (Fig. 2). This effect pointed out that anthranilic acid revealed better ability to stimulate biomass growth. Gained biomass growth, with and without addition of $\mathrm{Mg}$, was acceptable and its level was comparable to average obtained by the other authors (Praveen et al. 2009; White and Broadley 2009; Szopa et al. 2013).

The essential part of the conducted research was analysis of concentrations of the chosen bioelements $(\mathrm{Mg}, \mathrm{Cu}$, $\mathrm{Zn}, \mathrm{Fe}, \mathrm{Ca}, \mathrm{Na}, \mathrm{K}$ ) in in vitro shoot cultures of $\mathrm{B}$. monnieri which were enriched with $\mathrm{Mg}$ ions (added to the culture medium as magnesium sulfate) at increasing concentrations. On the basis of the obtained results, the significant influence of added organic compounds (serine, anthranilic acid) and $\mathrm{Mg}$ ions in various quantitative combinations on 


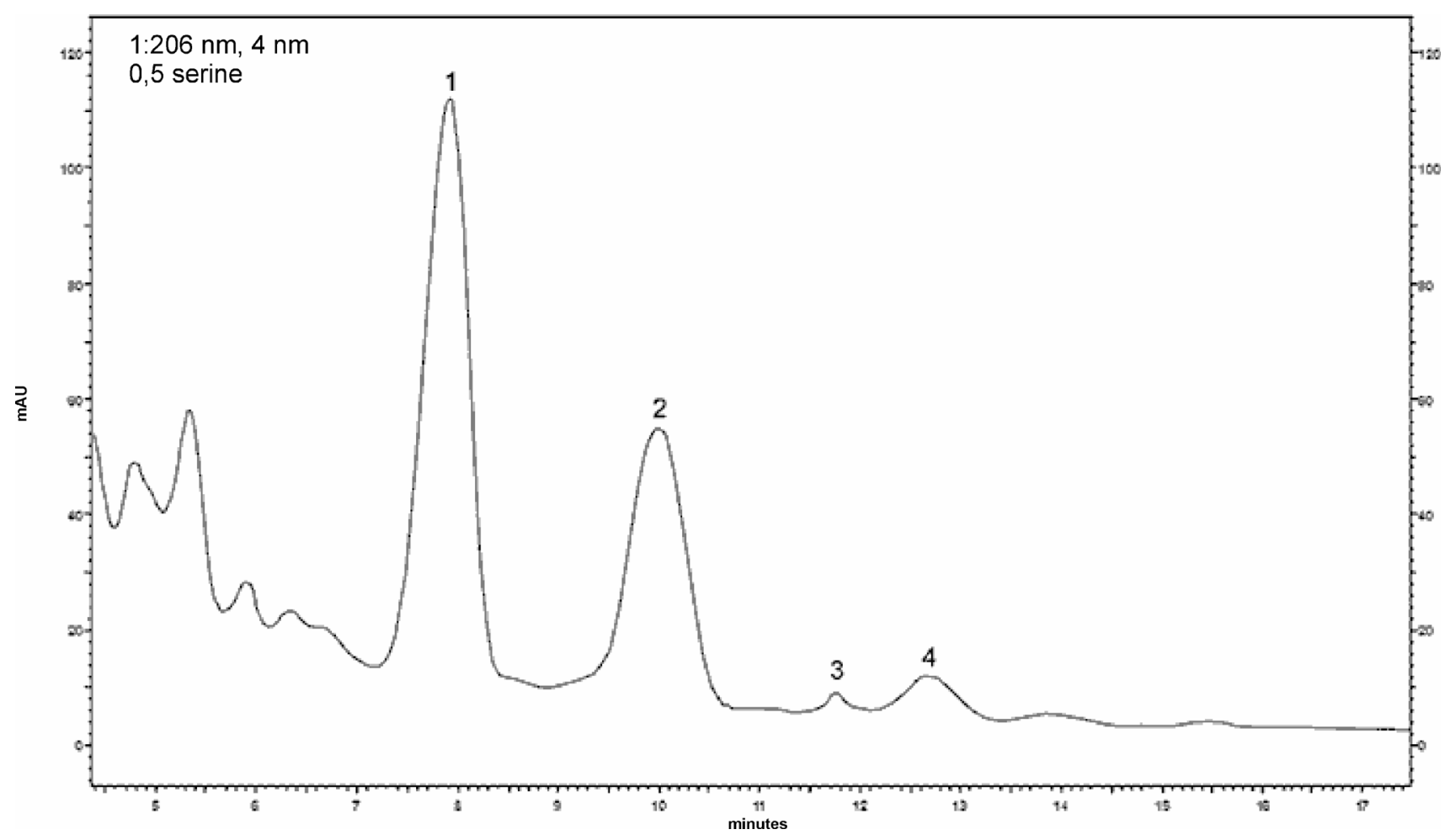

Fig. 1 An example RP-HPLC chromatogram of Bacopa monnieri extract on MS medium with 0.5 g/L serine addition: 1 Bacoside $\mathrm{A}_{3}, 2$ Bacoside II, 3 Bacoside X, 4 Bacoside C

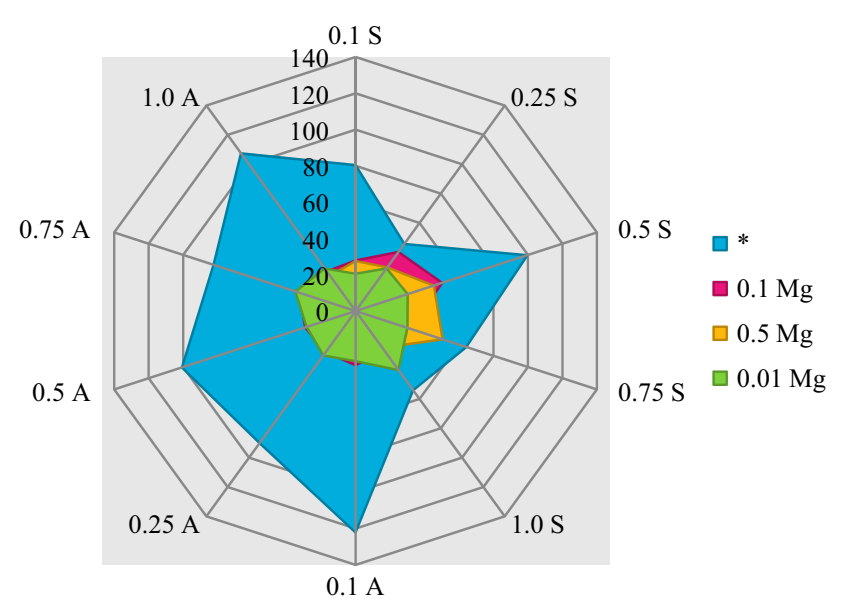

Fig. 2 Radar chart for biomass growth in obtained B. monnieri in vitro cultures. (A anthranilic acid, $S$ serine, asterisk in vitro cultures without $\mathrm{Mg}$, pink square supplement of $0.1 \mathrm{Mg}$, orange square supplement of $0.5 \mathrm{Mg}$, green square supplement of $0.01 \mathrm{Mg}$ )

accumulations of the chosen physiologically active bioelements in biomass of B. monnieri in vitro shoot cultures, were observed. The analyses of concentrations of the particular elements in biomass from in vitro cultures allowed clarifying correlations between their accumulation and biomass grown. Produced biomass of in vitro shoot cultures of B. monnieri (with serine or anthranilic acid) enriched with $\mathrm{Mg}$ ions was characterized by increased ability to accumulate this element. It is important to mention that in each of the discussed in vitro cultures, even for those of the smallest amount of magnesium added $(0.01 \mathrm{~g} /$ $\mathrm{L} \mathrm{Mg}$ ions), the concentration of this element in biomass was higher than for in vitro shoot cultures of $B$. monnieri without $\mathrm{Mg}$ addition, it equaled to $617.8 \mu \mathrm{g} / \mathrm{g}$ dry weight (DW) (Table 1). Moreover, taking into consideration in vitro cultures with serine, it was found that increase of $\mathrm{Mg}$ concentration in the medium from 0.01 to $0.5 \mathrm{~g} / \mathrm{L}$ resulted in noticeable increase of the element accumulation in biomass. It was true only for in vitro shoot cultures of $B$. monnieri with addition of low concentration of serine- 0.1 and $0.25 \mathrm{~g} / \mathrm{L}$. For higher supplementation of serine $(0.5$, $0.75,1.0 \mathrm{~g} / \mathrm{L}$ ), the increase of $\mathrm{Mg}$ concentration was small, and with addition of $0.1 \mathrm{~g} / \mathrm{L} \mathrm{Mg}$ the decreasing tendency was observed. Furthermore, it was noted that simultaneous supplementation of the medium with anthranilic acid and magnesium caused higher increase of this element accumulation in in vitro shoot cultures of $B$. monnieri than with serine addition alone. For each of the obtained in vitro cultures, increase of $\mathrm{Mg}$ accumulation was parallel with increased magnesium supplementation. In vitro culture with $0.5 \mathrm{mg} / \mathrm{L}$ of anthranilic acid and $1.0 \mathrm{~g} / \mathrm{L}$ of $\mathrm{Mg}$ resulted in the element concentration equal to $2163 \mu \mathrm{g} / \mathrm{g}$ 
DW (Table 1), and this was the highest accumulation determined. Nevertheless, the other in vitro cultures were not far from this most satisfactory result. The concentration of zinc in in vitro shoot cultures of $B$. monnieri was in the range $44.32-189.3 \mu \mathrm{g} / \mathrm{g} \mathrm{DW}$, however, for $B$. monnieri grown in a liquid medium culture without any supplements, it equaled to $110.1 \mu \mathrm{g} / \mathrm{g} \mathrm{DW}$ (Table 1). In vitro shoot cultures of B. monnieri with addition of serine or anthranilic acid supported with $\mathrm{Mg}$ indicated the lack of noticeable increase of zinc accumulation ability in most cases. Similar tendency was reported in other studies concerning this plant (Łojewski et al. 2014). The concentration of copper (Table 1) in in vitro shoot cultures of B. monnieri was in a range $0.745-2.976 \mu \mathrm{g} / \mathrm{g} \mathrm{DW}$. The amount of $\mathrm{Cu}$ in in vitro shoot cultures of $B$. monnieri cultivated on liquid medium cultures without any supplements was $1.102 \mu \mathrm{g} / \mathrm{g}$ DW. Addition of serine or anthranilic acid in both cases without $\mathrm{Mg}$ did not cause significant increase of $\mathrm{Cu}$ accumulation; the results were: $0.745-1.437 \mu \mathrm{g} / \mathrm{g}$ DW. The most meaningful effect of increased $\mathrm{Cu}$ accumulation was obtained in in vitro cultures with $0.25 \mathrm{~g} / \mathrm{L}$ serine and $0.1 \mathrm{~g} /$ $\mathrm{L} \mathrm{Mg}(2.560 \mu \mathrm{g} / \mathrm{g} \mathrm{DW})$ as well as, in in vitro cultures with $0.75 \mathrm{mg} / \mathrm{L}$ anthranilic acid and $0.25 \mathrm{~g} / \mathrm{L} \mathrm{Mg}(2.976 \mu \mathrm{g} / \mathrm{g}$ $\mathrm{DW})$. Another studies revealed that the addition of $\mathrm{Mg}$ and organic compounds increased the level of $\mathrm{Cu}$ in plants (White and Broadley 2009; Kumar et al. 2009). The concentration of iron without any supplement in in vitro shoot cultures of B. monnieri (control) reached $103.2 \mu \mathrm{g} / \mathrm{g} \mathrm{DW}$ (Table 1). In this case, serine or anthranilic acid enrichment without $\mathrm{Mg}$ caused increase of Fe accumulation in the obtained biomass in range of 132.1-189.5 $\mu \mathrm{g} / \mathrm{g} \mathrm{DW}$ (Table 1). Moreover, the most satisfactory accumulation of $\mathrm{Fe}$ in in vitro shoot cultures of B. monnieri $(259.6 \mu \mathrm{g} / \mathrm{g}$ DW), was noticed for in vitro culture enriched in $0.5 \mathrm{mg} / \mathrm{L}$ anthranilic acid and $0.25 \mathrm{~g} / \mathrm{L}$ of $\mathrm{Mg}$. Other studies showed synergism between $\mathrm{Zn}$ and $\mathrm{Fe}$, while $\mathrm{Mg}$ content was not affected by $\mathrm{Zn}$ levels (Gunesa et al. 1998). Concentration of potassium in the obtained in vitro shoot cultures of $B$. monnieri without any supplementation was high and reached $12,300 \mu \mathrm{g} / \mathrm{g}$ DW (Table 1 ). The accumulation of $\mathrm{K}$ in biomass with serine was in the range from 16,807 to $27,950 \mu \mathrm{g} / \mathrm{g}$ DW while in the biomass with addition of anthranilic acid was in the range of $20,560-26,040 \mu \mathrm{g} / \mathrm{g}$ DW (Table 1). In in vitro shoot cultures of B. monnieri containing serine and $\mathrm{Mg}$, increase of $\mathrm{K}$ concentration in the obtained biomass was highest in media containing up to $0.1 \mathrm{~g} / \mathrm{L}$ of added $\mathrm{Mg}$. Higher concentrations of magnesium in the culture medium led to decrease of $\mathrm{K}$ accumulation in biomass. In case of medium containing anthranilic acid, the higher was $\mathrm{Mg}$ concentration, the higher was $\mathrm{K}$ concentration in the biomass (up to $58,970 \mu \mathrm{g} / \mathrm{g} \mathrm{DW}$ in the medium containing $0.25 \mathrm{~g} / \mathrm{L}$ of anthranilic acid and $1 \mathrm{~g} / \mathrm{L}$ of $\mathrm{Mg}$ ) (Table 1).
Such high levels of potassium in the studied biomass were approximately four times higher than in dried fruits, one of the best sources of this element (Jarosz 2012).

Concentration of sodium in the obtained in vitro shoot cultures of $B$. monnieri with the addition of serine was in the range of 574.1-1289 $\mu \mathrm{g} / \mathrm{g}$ DW. In in vitro cultures with anthranilic acid, sodium concentration ranged from 279.2 to $808.4 \mu \mathrm{g} / \mathrm{g} \mathrm{DW}$ (Table 1). It was noticed that for in vitro shoot cultures of $B$. monnieri enriched in serine, the ability for bioaccumulation of $\mathrm{Na}$ increased simultaneously with the increase of $\mathrm{Mg}$ addition to $0.1 \mathrm{~g} / \mathrm{L}$. The addition of magnesium above this level caused decrease of the element accumulation. Regarding the in vitro cultures supplemented with anthranilic acid it was observed that the best results were obtained for in vitro cultures with the addition of anthranilic acid only; supplementation of $\mathrm{Mg}$ caused decrease of $\mathrm{Na}$ accumulation in B. monnieri shoots from in vitro cultures. Performed analyses of the amount of calcium accumulated in in vitro cultures indicated that in the media enriched with serine, the level of $\mathrm{Ca}$ slightly increased for cultures in which $\mathrm{Mg}$ concentration was 0.01 and $0.1 \mathrm{~g} / \mathrm{L}$. The addition of $\mathrm{Mg}$ in higher concentration $(0.5 \mathrm{~g} / \mathrm{L})$ caused decrease of $\mathrm{Ca}$ accumulation in in vitro shoot cultures of B. monnieri (Table 1). Similar effect was observed in the case of $B$. monnieri in vitro shoot cultures with anthranilic acid. The ability of $\mathrm{Ca}$ accumulation increased when B. monnieri in vitro culture media were enriched with $\mathrm{Mg}(0.25$ and $0.5 \mathrm{~g} / \mathrm{L})$, but the addition of this element in $1.0 \mathrm{~g} / \mathrm{L}$ concentration caused significant stoppage of $\mathrm{Ca}$ accumulation in in vitro shoot cultures of $B$. monnieri.

The increased accumulation of the elements in $B$. monnieri shoots in media enriched with serine and anthranilic acid is a result of formation of low molecular weight (metal-organic particle) chelates, being easily transported through biological membranes and accumulated in the tissues. That is the reason, why $B$. monnieri is used in metals remediation (Hill and Curran 1960; Childs 1971).

In earlier research, similar phenomenon of bioaccumulation of the chosen physiologically active bioelements in fruiting bodies or in in vitro culture mycelium was observed (Łojewski et al. 2014).

Concentration of bacosides in the biomass of in vitro shoot cultures of $B$. monnieri in relation to the medium composition was determined. It was found that comparing to the control medium (MS1), addition of anthranilic acid leads to increase of bacosides concentration in biomass. Addition of $\mathrm{Mg}$ to the medium containing anthranilic acid caused substantial decrease of bacosides concentration in biomass. Considering the other organic compound addition to the medium (serine), a positive correlation between the concentration of $\mathrm{Mg}$ in the medium and bacosides 


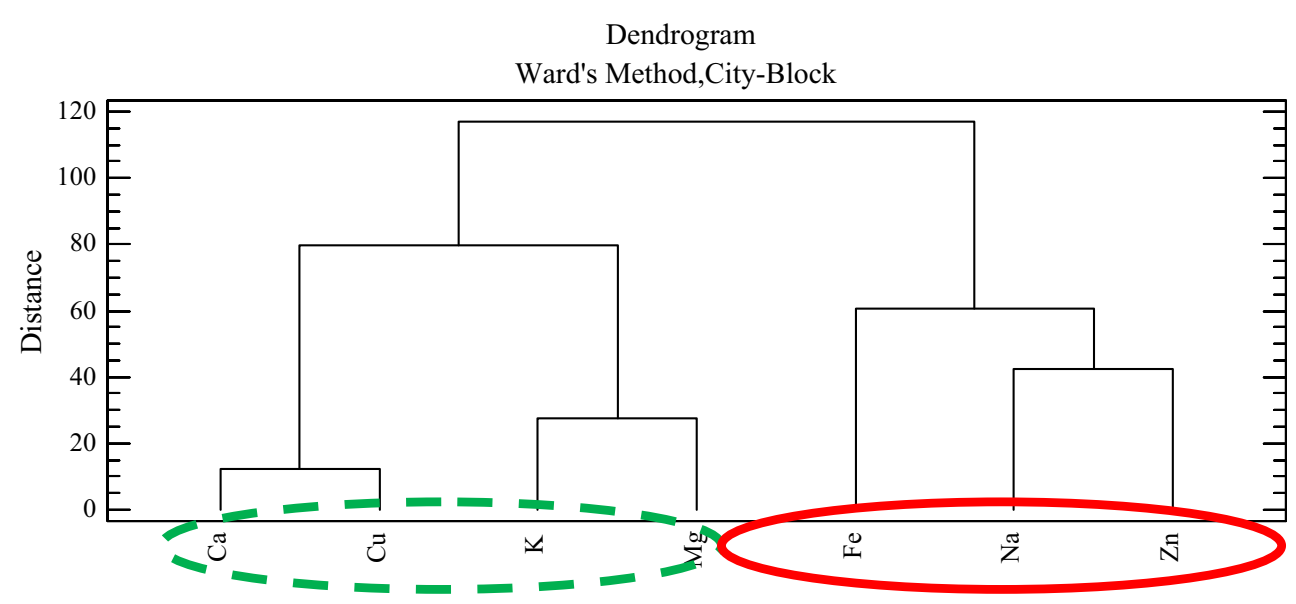

Fig. 3 Dendogram presenting similarity of the analyzed bioelements ( $\mathrm{Cu}, \mathrm{Ca}, \mathrm{K}, \mathrm{Mg}, \mathrm{Fe}, \mathrm{Na}, \mathrm{Zn}$ ); (green dashed line) first cluster, (red continuous line) second cluster

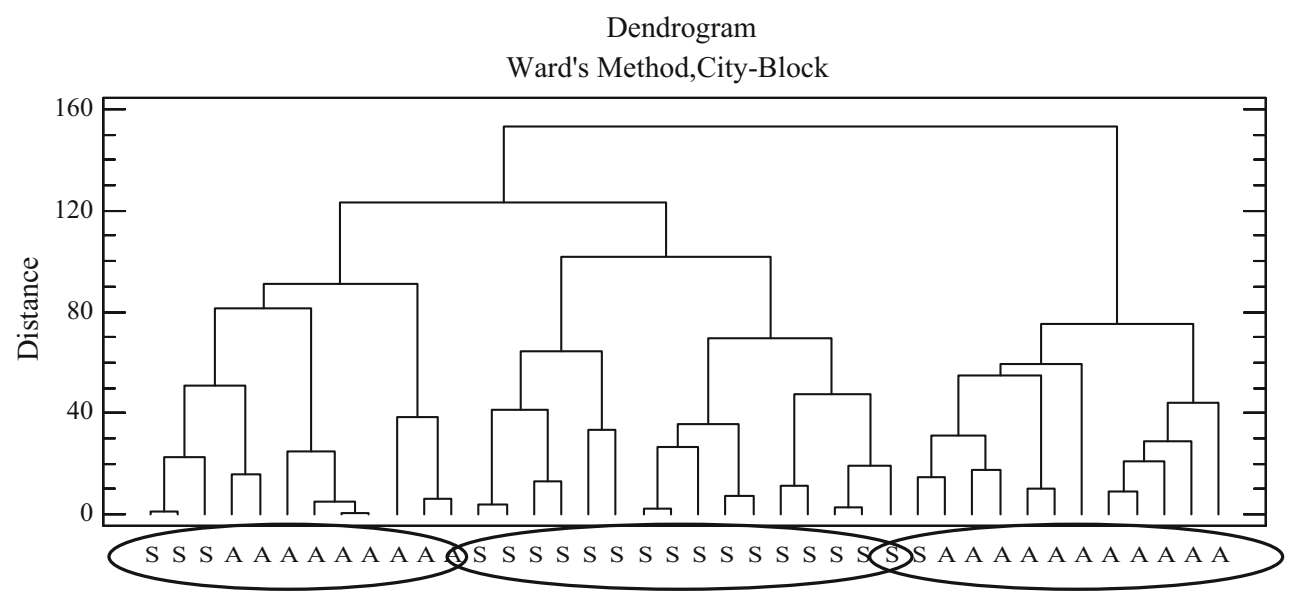

Fig. 4 Dendrogram presenting similarity between B. monnieri in vitro cultures enriched in $A$ anthranilic acid, $S$ serine

concentration in biomass is visible. The best results were observed at medium serine concentrations $0.25-0.75 \mathrm{~g} / \mathrm{L}$. Addition of serine alone (without magnesium ions) caused lowering of bacosides concentration in the plant. Summarizing, the highest concentration of bacosides in the biomass of B. monnieri in vitro culture was determined in the media (MS1) containing combination of serine and $\mathrm{Mg}$ ions $(0.25 \mathrm{~g} / \mathrm{L}$ of serine and $0.1 \mathrm{~g} / \mathrm{L}$ of $\mathrm{Mg}$ and $0.5 \mathrm{~g} / \mathrm{L}$ of serine and $0.5 \mathrm{~g} / \mathrm{l}$ of $\mathrm{Mg}$ ) and reached $37.3 \mathrm{mg} / \mathrm{g} \mathrm{DW}$.

\section{Chemometric analysis}

The results of the performed research (data collected in Table 1), forty objects (biomass obtained in in vitro shoot cultures of $B$. monnieri of variable medium composition) described by seven variables (concentrations of $\mathrm{Mg}, \mathrm{Ca}$, $\mathrm{Cu}, \mathrm{Zn}, \mathrm{Fe}, \mathrm{K}, \mathrm{Na}$ ), revealed high diversity. The addition serine or anthranilic acid in five concentrations combinations $(0.1,0.25,0.5,0.75,1.0 \mathrm{~g} / \mathrm{L})$ were considered. In other experiments, the addition of $\mathrm{Mg}$ (concentrations: $0.01,0.1,1.0 \mathrm{~g} / \mathrm{L}$ ) to the in vitro culture media (containing serine or anthranilic acid) was also examined. Very wide range of metals' concentrations variability which was observed (from $0.745 \mu \mathrm{g} / \mathrm{g}$ for $\mathrm{Cu}$ to $58,970 \mu \mathrm{g} / \mathrm{g}$ for $\mathrm{K}$ ) caused that an unambiguous interpretation of the obtained results was difficult. Hence, chemometric tools helpful in such kind of analyses were used.

Cluster analysis (CA) allows, out of the whole set of data, separation of the groups (clusters) of objects or features which are characterized by similar variability. In this approach, city block was applied as a distance measure and calculated the distance between the obtained clusters on the basis of Ward's agglomeration method. Similarity of features (variation of concentrations of the analyzed elements-Fig. 3) and objects (in vitro cultures-Fig. 4) is discussed. In the Figs. 3 and 4, the dendrograms (colloquially called trees) are shown in which axis $x$ represents the examined element (Fig. 3) or the analyzed in vitro 
cultures (Fig. 4) while axis $y$ stands for the distance between the objects (Gemperline 2006; Massart et al. 1998; Mazerski 2000; Otto 1999; Kramer 1996).

Considering the first dendrogram (Fig. 3), two main clusters can be distinguished. The first contains $\mathrm{Ca}, \mathrm{Cu}, \mathrm{K}$ and $\mathrm{Mg}$ (green dashed line) and the second consists of $\mathrm{Fe}$, $\mathrm{Na}, \mathrm{Zn}$ (red continuous line). It is important to underline that the shorter are lines representing elements on the dendrogram, the more similar are changes of concentrations of the considered elements. Belonging of the bioelements $(\mathrm{Ca}, \mathrm{Cu}, \mathrm{K}, \mathrm{Mg}$ and $\mathrm{Fe}$ - the first group, $\mathrm{Na}$ and $\mathrm{Zn}$ - the second one) to the separate clusters is justified physiologically and scientifically confirmed. Increased concentration of $\mathrm{Fe}$ increases hydration and permeability of the cytoplasm for $\mathrm{Cu}$ and $\mathrm{Mg}$. Moreover, in plants there is a natural synergy between $\mathrm{K}$ and $\mathrm{Mg}$. Additionally it was found that increase of $\mathrm{Cu}$ content in plants is accompanied by increase of $\mathrm{Mg}$ level. All these aspects have decided that $\mathrm{Ca}, \mathrm{Cu}, \mathrm{K}$ and $\mathrm{Mg}$ belong to the same group.

On the other hand, correlation between the first and the second cluster does not exist as they are placed on different lines of the dendrogram. This situation emphasizes natural antagonism observed in plants' tissues between $\mathrm{Cu}$ and $\mathrm{Zn}$ as well as between $\mathrm{Mg}$ and $\mathrm{Na}$. That is a consequence of plants structure, and relates to the elements role in the activation of enzymatic systems and competition in complexation of the same organic complexes (Hopinks and Hüner 2004; Kopcewicz and Lewak 2002; Kumar et al. 2009; Taiz and Zeiger 2005; White and Broadley 2009).

Considering the second dendrogram, which presents similarity of objects (Fig. 4), three visible clusters can be observed. One of them consists of in vitro cultures enriched with serine and anthranilic acid without $\mathrm{Mg}$ addition. The second large group of similar objects includes in vitro cultures with the addition of serine and $\mathrm{Mg}$, and the third cluster consists of in vitro cultures with anthranilic acid and magnesium. Undoubtedly, composition of the culture medium determines elements concentration levels in the resulting plant material. Serine and anthranilic acid influence the mechanism of metals uptake and their accumulation. The same can be concluded regarding the addition of magnesium.

It can be definitely stated that the obtained in vitro shoot cultures of $B$. monnieri are similar within the scope of a given group. Depending on the plant species, type of cultivation and the environment, there are significant differences in basic aspects related to its nutrition and uptake of ions, mechanism of transport or rate of accumulation. Distinct course of elements' concentrations changes in the cultures with the addition of serine may be the result of its chemical properties, namely the tendency to complex $\mathrm{Zn}$ and $\mathrm{Cu}$ ions (the same number of coordination $\mathrm{LK}=4$ ). In contrast, the addition of anthranilic acid to the in vitro culture medium creates acidic $\mathrm{pH}$ which promotes uptake and transport of $\mathrm{Ca}, \mathrm{Mg}$ and $\mathrm{K}$ in plant (Hopinks and Hüner 2004: Kumar et al. 2009; White and Broadley 2009).

Principal component analysis (PCA) was used as the second method supporting interpretation of the obtained data (Massart et al. 1998; Mazerski 2000; Otto 1999; Kramer 1996). It allows to reduce the amount of variables describing the objects (in vitro cultures) analyzed in this study. In this case, forty objects (in vitro cultures) characterized by seven functions (concentrations of metals) were analyzed. The reduction of number of variables is based on the change of the correlated input data into a set of new combination of orthogonal variables. In this case, the new orthogonal variables, called principal components (C1, C2, C3), describe above $80.1 \%$ of variability of the considered data set. Variables C1, C2, C3 are linear combinations of input variables (Massart et al. 1998; Mazerski 2000; Otto 1999; Kramer 1996), multiplied by the certain load values - eigenvalues (Table 2). Eigenvalue determines the level of saturation of a certain variable and is equal to correlation factor between the input variables and the outcome variables (Massart et al. 1998; Mazerski 2000; Otto 1999; Kramer 1996). Table 2 shows eigenvalues for the obtained three principal components.

The higher the value of the factor describing main component is, the more important its impact on object group's changeability is (Otto 1999; Kramer 1996). On this basis, it could be pointed out that concentrations of $\mathrm{Ca}, \mathrm{Cu}$, $\mathrm{K}$ have the greatest impact on the first principal component: $\mathrm{C} 1$, the principal component $\mathrm{C} 2$ is mainly influenced by the changes of $\mathrm{Na}$ and $\mathrm{Zn}$ concentrations and so on. As a result, the obtained three principal components are allowed to present the data in a three-dimensional space (Fig. 5). The presented scatter plot clearly indicates similarities between the in vitro shoot cultures of $B$. monnieri in relation to the culture medium composition. It can be observed that two groups of objects are scattered in the graph space. The first of them (blue line) consists of in vitro shoot cultures of $B$. monnieri with serine added to the culture medium. The second cluster consists of in vitro

Table 2 Table presenting eigenvalue for certain principal components $(\mathrm{C} 1, \mathrm{C} 2, \mathrm{C} 3)$

\begin{tabular}{lccc}
\hline & Component 1 & Component 2 & Component 3 \\
\hline $\mathrm{Ca}$ & 0.464668 & -0.146163 & 0.410857 \\
$\mathrm{Cu}$ & 0.493211 & 0.158732 & 0.202461 \\
$\mathrm{Fe}$ & 0.293015 & 0.303272 & 0.498783 \\
$\mathrm{~K}$ & 0.491718 & -0.226665 & -0.27072 \\
$\mathrm{Mg}$ & 0.4121 & 0.198343 & -0.6133 \\
$\mathrm{Na}$ & -0.195731 & 0.590832 & 0.169611 \\
$\mathrm{Zn}$ & 0.0710349 & 0.649359 & -0.251451 \\
\hline
\end{tabular}




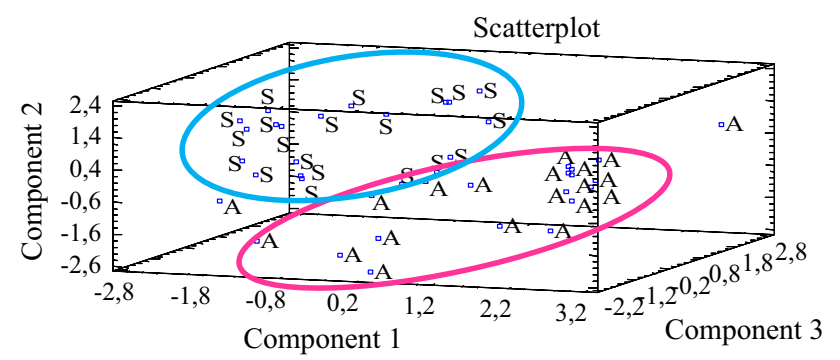

Fig. 5 Scatter plot-based on main components C1, C2, C3 in threedimensional space representing the clusters of data, $A$ (in vitro cultures with anthranilic acid), $S$ (in vitro cultures with serine)

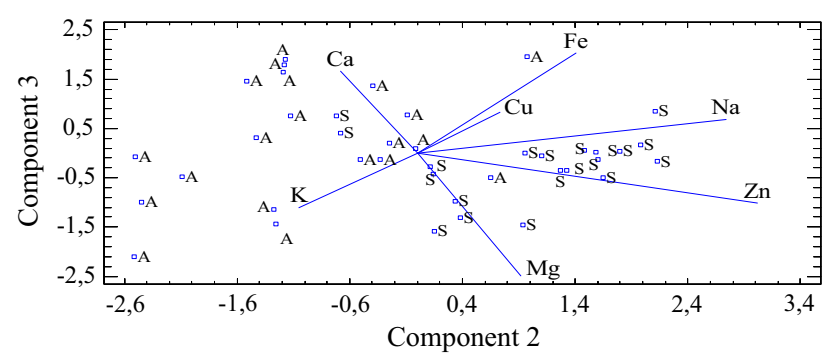

Fig. 6 Biplot graph based on the main components C2, C3-shows the tendency to changes in chosen elements concentration in obtained B. monnieri in vitro cultures ( $\mathrm{A}-\mathrm{in}$ vitro cultures enriched in anthranilic acid, $\mathrm{S}$-in vitro cultures enriched in serine)

cultures grown on medium enriched with anthranilic acid (pink line). This result as well as close location of the points confirms that there is close similarity between the analyzed features within each group. Furthermore, on the basis of the biplot graph (Fig. 6), which was built of components $\mathrm{C} 2$ and $\mathrm{C} 3$, the relationships between the changes of the certain elements (metals) concentrations in individual in vitro cultures can be investigated. It is clear that in vitro cultures with anthranilic acid are characterized by the highest bioaccumulation of $\mathrm{K}$ and $\mathrm{Ca}$, what confirms earlier interpretation. The tendency to accumulate $\mathrm{Na}, \mathrm{Zn}$ or $\mathrm{Cu}$ in plant material was higher in in vitro shoot cultures of B. monnieri enriched with serine. The addition of $\mathrm{Mg}$ ions to in vitro cultures does not influence accumulation of this element which is also visible on the Biplot (the line directed down).

\section{Conclusions}

Due to the fact that $B$. monnieri is a protected by law plant species, and that use of natural raw materials in pharmaceutical preparations requires standardization, it is really important to obtain reproducible material of the desired properties from in vitro cultures. It was proved that the culture medium, enriched with serine and anthranilic acid with and without the addition of magnesium ions, provides means to obtain the plant material rich in the essential bioelements ( $\mathrm{Mg}, \mathrm{Zn}, \mathrm{K}, \mathrm{Ca}, \mathrm{Cu}, \mathrm{Na}, \mathrm{Fe}$ ). It also promotes accumulation of bacosides in the plant biomass. All these elements and compounds are responsible for curative effects of the B. monnieri preparations used in traditional medicine (for example the anti-depressant function of elements $\mathrm{Mg}, \mathrm{Zn}$ and $\mathrm{Cu}$ ). Considering the observed shortage of plant reserves in the natural environment and its curative properties, it seems to be of utmost importance to obtain material, as a result of the presented experimental in vitro shoot cultures of $B$. monnieri, characterized by optimal and reproducible composition of physiologically active elements and metabolites.

Author contribution statement M. Łojewski: in vitro culture of Bacopa monnieri, A. Krakowska: chemometric analysis, W. Reczyński: AAS analysis, A. Szewczyk: Bacosides HPLC analysis and B. Muszyńska: extract preparing, author of idea of the work and text.

Open Access This article is distributed under the terms of the Creative Commons Attribution 4.0 International License (http://crea tivecommons.org/licenses/by/4.0/), which permits unrestricted use, distribution, and reproduction in any medium, provided you give appropriate credit to the original author(s) and the source, provide a link to the Creative Commons license, and indicate if changes were made.

\section{References}

Ahire ML, Walunj PR, Kishor PBK, Nikam TD (2013) Effect of sodium chloride-induced stress on growth, proline, glycine betaine accumulation antioxidative defence and bacoside A content in in vitro regenerated shoots of Bacopa monnieri (L.) Pennell. Acta Physiol Plant 35:1943-1953

Allen LH (1982) Calcium bioavailability and absorption: a review. Am J Clin Nutr 4:783-808

Biswas SK, Das I, Chowdhury A, Karmakar UK, Hossain H (2012) Evaluation of antinociceptive and antioxidant activities of whole plant extract of Bacopa monniera. Res J Med Plant 6:607-614

Childs CW (1971) Calcium(I1) and magnesium(I1) binding by LSerine orthophosphate in aqueous solutions. Can J Chem 49:2359-2364

De Baaij JHF, Hoenderop JGJ, Bindels RJM (2015) Magnesium in man: implications for health and disease. Physiol Rev 95:1-46

Gemperline P (2006) Practical guide to chemometrics. Taylor \& Francis, Boca Raton

Gohil KJ, Patel JA (2010) A review on Bacopa monnieri: current research and future prospects. Int J Green Pharm 4:1-9

Gunesa A, Alpaslana M, Inala A (1998) Critical nutrient concentrations and antagonistic and synergistic relationships among the nutrients of NFT-grown young tomato plants. J Plant Nutr 21:2035-2047

Hill AG, Curran C (1960) Infrared and ultraviolet absorption spectra of some salts and metal chelates of anthranilic acid. J Phys Chem 64:1519-1522

Hopinks WG, Hüner NPA (2004) Introduction to plant physiology. Wiley, New York 
Jarosz M (ed) (2012) The Polish population nutrition standardsamendment. Food and Nutrition Institute, Warsaw

Jyoti A, Sharma D (2006) Neuroprotective role of Bacopa monnieri extract against aluminium induced oxidative stress in the hippocampus of rat brain. Neurotoxicol 27:451-457

Kamkaew N, Norman Scholfield C, Ingkaninan K, Taepavarapruk N, Chootip K (2013) Bacopa monnieri increases cerebral blood flow in rat independent of blood pressure. Phytother Res 27:135-138

Kopcewicz J, Lewak S (2002) Fizjologia Roślin. Wydawnictwo naukowe PWN, Warszawa

Kramer R (1996) Chemometric techniques for quantitative analysis. Taylor \& Francis, London

Kumar R, Mehrota NK, Nautiyal BD, Kumar P, Singh PK (2009) Effect of copper on growth, yield and concentration of Fe, Mn, $\mathrm{Zn}$ and $\mathrm{Cu}$ in wheat plants (Triticum aestivum $\mathrm{L}$.). J Environ Biol 30:485-488

Livingstone C (2015) Zinc: physiology, deficiency, and parenteral nutrition. Nutr Clin Pract 30:371-382

Łojewski M, Muszyńska B, Smalec A, Reczyński W, Opoka W, Sułkowska-Ziaja K (2014) Development of optimal medium content for bioelements accumulation in Bacopa monnieri (L.) in vitro culture. Appl Biochem Biotechnol 174:1535-1540

Massart MBG, Vandeginste LMC, Buydens S, De Jong PJ, Lewi J (1998) Handbook of chemometrics and qualimetrics: part A. Elsevier, Amsterdam

Mazerski J (2000) Podstawy chemometrii. Wyd. Politechniki Gdańskiej, Gdańsk (in Polish)

Murashige T, Skoog F (1962) A revised medium for rapid growth and bioassays with tobacco tissue cultures. Physiol Plant 15:473-497

Otto M (1999) Chemometrics-statistics computer application in analytical chemistry. Wiley, New York

Praveen N, Naik PM, Manohar SH, Nayeem A, Murthy HN (2009) In vitro regeneration of brahmi shoots using semisolid and liquid cultures and quantitative analysis of bacoside A. Acta Physiol Plant 31:723-728
Ravikumar S, Nazar S, Nuralshiefa A, Abideen S (2005) Antibacterial activity of traditional therapeutic coastal medicinal plants against some pathogens. J Environ Biol 26:383-386

Shah M, Behara YR, Jagadeesh B (2012) Phytochemical screening and in vitro antioxidant activity of aqueous and hydroalcoholic extract of Bacopa monnieri Linn. Int J Pharm Sci Res 3:3418-3424

Singh HK (2013) Brain enhancing ingredients from? Ayurvedic medicine: quintessential example of Bacopa monnieri, a narrative review. Nutrients 5:478-497

Srivastava P, Raut HN, Puntambekar HM, Desai AC (2012) Stability studies of crude plant material of Bacopa monnieri and quantitative determination of Bacopaside I and Bacoside A by HPLC. Phytochem Anal 23:502-507

Sumathi T, Shobana C, Christinal J, Anusha C (2012) Protective effect of Bacopa monnieri on methyl mercury-induced oxidative stress in cerebellum of rats. Cell Mol Neurobiol 32:979-987

Szopa A, Ekiert H, Muszyńska B (2013) Accumulation of hydroxybenzoic acid and other biologically active phenolic acids in shoot and callus cultures elements often lacking in human dietsiron, zinc, copper, calcium, magnesium, selenium and iodine. New Phytol 182:49-84

Taiz L, Zeiger E (2005) Plant physiology. Sinauer Associates, Sunderland

Vangalapati MA, Bammidi SR, Volluri SS, Chippada SC, Avanigadda S (2011) Review on pharmacological studies of Bacopa monniera. JCBPS 1:250-259

Wasnik U (2012) Evaluation of anticonvulsant activity on leaves of alcoholic extract of Bacopa monnieri Linn. Intl J Pharm Sci Rev Res 17:1-5

White PJ, Broadley MR (2009) Biofortification of crops with seven mineral elements often lacking inhuman diets-iron, zinc, copper, calcium, magnesium, selenium and iodine. New Phytolog 182:49-84 